By F. J. HARSAGHY, JR.

\title{
Roads to Aeronautical Research
}

Mr. Harsaghy is reviews editor, Institute of the Aeronautical Sciences, New York.

\section{INTRODUCTION}

$\mathrm{T}$

HE ROADS to aeronautical research are many: broad and narrow. They reach as a network all over the world, having been built by governmental and private agencies for various purposes. Ultimately, in this expanding air age in which we live, they lead to both war and peace.

At the important crossroads of the world stand institutes, foundations, associations, societies, and other bodies in whose libraries and research facilities far-reaching investigations are being conducted. Of the many different types of bodies furthering the field of aeronautical research, the Royal Aeronautical Society in Britain, the National Aeronautical Research Institutes in the Netherlands and in Sweden, Massachusetts Institute of Technology and the National Advisory Committee for Aeronautics in the United States are but a token few. Among such eminent bodies, we find the Institute of the Aeronautical Sciences, ${ }^{1}$ with its headquarters located in New York.

The objective of this paper is to describe the functioning of the IAS library in New York City and of the IAS documentation service which is published monthly in the Aeronautical Engineering Review, an official IAS publication.

\section{Part I-Library Services}

The principal aim of the Institute library in New York is to provide the reader or researcher with the literature required to further investigations and research. This

\footnotetext{
1 Hereinafter referred to as IAS.
}

aim is directly related to the stated official policy of the Institute itself which seeks to facilitate the interchange of ideas among persons interested in the advancement of the aeronautical sciences.

The history of the library goes back to the founding of the IAS in 1932. However, the largest portion of the collection was added in 1940, when the W.A.M. Burden Library was loaned to the IAS and the Paul Kollsman Lending Library was started. In 1950, the collections of the W.A.M. Burden Library became an integral part of the Institute library. This accretion made available extensive and additional coverage on both general aeronautical topics and on specific technical phases, some of which will be enumerated in Part II, as part of a subject breakdown.

The Institute library provides various functional services to a potential readership of over 10,000 individual and corporate members who are entitled to use library and informational facilities. Among these services, the reading and reference, circulation, and duplicating services (photostating, microfilming, etc.) are of prime importance.

The library collection consists of approximately 50,000 items, of which about 18,000 are well-selected books. The remainder of the collection is made up of scientific and technical reports from all over the world, periodicals, pamphlets, films, and miscellaneous and ephemeral materials. IAS members may borrow these library materials for a period of two weeks (with renewal privileges); excepted are certain reference works and rare items. Others over eighteen years old with well-defined aeronautical interests 
and residing in the United States may apply for membership in the Paul Kollsman Lending Library, which would permit them to borrow books and, as far as facilities permit, other research materials.

In the case of rare items, the independently functioning IAS Aeronautical $\mathrm{Mu}-$ seum has a close cooperative working arrangement with the library. One activity which illustrates this cooperative arrangement deals with the Institute's collections of Wright memorabilia, which were used extensively last year to commemorate the historic Fiftieth Anniversary of Powered Flight.

The IAS library in New York also maintains a working arrangement with the Institute's Pacific Aeronautical Library in Los Angeles. The PAL is under the direction of Mrs. Nell Steinmetz and functions as an independent activity serving the technical libraries of the West Coast aviation industry by providing them with essential day-to-day information needed to carry on their defense effort. To a lesser extent this same type of relationship likewise is being maintained with the IAS library in San Diego.

Some 300 pieces of library materials are circulated from the New York library per month. For this purpose the postal service is used extensively, with books being mailed to distant points in the United States and Canada as one means of maintaining connections with the far-flung membership.

The Institute library in New York functions with a regular staff of seven persons, including the librarian, John J. Glennon. Administratively, it is an integral part of the Institute, which is a scientific membership society deriving financial support directly from the aircraft industry.

In short, the fundamental purpose of this IAS library is to provide functional and professional specialized library service furthering the aeronautical sciences.

\section{Part II-Aeronautical Reviews}

The "Aeronautical Reviews" section which is published monthly in the Aeronautical Engineering Review, and which is cumulated annually as the Aeronautical Engineering Index, is an important part of the informational and editorial services of the IAS. The Reviews Department functionally may be considered to be the indexing and abstracting arm of the library. Consequently, a perfectly coordinated and smoothly functioning liaison has been established and is being maintained between the Editorial Reviews Department and the library organization.

The policy determining "Aeronautical Reviews" coverage stems directly from the stated basic mission of the Institute as a whole. The director of the Institute, S. Paul Johnston, in an editorial published in the April, 1950, issue of the Aeronautical Engineering Review, on page 17, has emphasized that:

The basic mission of the Institute is to facilitate the interchange of ideas among aeronautical engineers to advance the aeronautical sciences.

And in an earlier editorial, published January, 1947, (ibid.), on page 21 , he has stated certain principles still having validity today:

With the release of wartime restrictions on information, more and more significant articles are appearing in the technical press at home and abroad, and it is more important than ever that IAS members everywhere be given a brief, accurate, and current evaluation of them as fast as they appear. With this in view, the Institute staff has been reorganized to bring the libraries and the Review closer together..., to extend the quantity and quality of our coverage. Classification of articles is being intensively studied and improved. Abstracts are being briefed by elimination of extraneous matter. A new style of presentation has been adopted which is consistent with 
other technical abstracting services and which is geared into the indexing systems of technical libraries.

With the phenomenal growth of aeronautics, keeping pace with its vast literature and that of related fields has developed into a voluminous task. The tremendous weight of the coverage now being written up in publications all over the world requires a very strictly defined basis for selection of items to be included in the Review. Thus, only that literature is considered for inclusion which reports results of original theoretical or experimental studies, or is concerned with new developments in techniques, processes, or instrumentation. Extensive authoritative summaries also are included. Articles written solely from the standpoints of news or popularization are excluded.

Subject-wise, within a classified treatment, aspects of aerodynamics, airplane design, power plants, structures, research, wind tunnels, and flight operating problems are given primary emphasis in the selection process. Other elements such as aeroelasticity, airports, flight testing, fuels and lubricants, gliders, lighter-than-air craft, specialized equipment, instruments, materials, missiles, parachutes, propellers, safety, and thermodynamics also are covered. In addition, there are many related fields which are included in this coverage because of the important bearing on the aeronautical sciences. Among them are air transportation, aviation medicine, computers, education and training, electronics, laws and regulations, machine elements, mathematics, mechanics and physics, meteorology, military aviation, navigation, ordnance and armament, photography, aircraft production, and space travel.

The main development of the coverage technique was started during the latter part of 1946 . Prior to that date it was usual to carry large numbers of items of very general interest. The September, 1946, issue of the Aeronautical Engineering Review, for example, carried but 135 reviews of which approximately $50 \%$ were news or popular items, in many cases, of only current interest. This contrasts sharply with the coverage for September, 1953, when 416 items were included. Of these 217 were carried with annotations and the remaining 199 were listed, each with a descriptive title, author or authors usually, and the source. The subjects included in these 416 items were confined entirely to the three strictly defined coverage categories listed above. Without doubt the presently used selection process-aimed at the maintenance of currency and at the broadest possible coverage of useful items in the literature-and the system of brief item citations developed during the past several years to carry out these aims are to be credited for this large increase in coverage.

A better appreciation may be had by considering the magnitude of the problem facing the Reviews Department and the library sharing the responsibility of determining selection policies. Regularly, approximately 500 specialized periodicals and serials are received at the Institute. Of these approximately 200 are weeded out in the library without being routed into the Reviews Department for various reasons, including that of limited scope, over-specialization of coverage, and because of difficulties in the use of certain foreign materials. Of the remaining 300, approximately $50 \%$ are always used as sources and $30 \%$ are used to a lesser extent. The remaining $20 \%$ are used only occasionally. In addition, an average of approximately 175 reports each month are routed into the Reviews Department after initial processing by the library. These reports constitute perhaps the most important group of materials covered in the Review, for generally they 
represent the results of original research, enlargements or extensions of theoretical and experimental studies, and new developments in techniques, procedures, or instrumentation. They are channeled to the Institute from all over the world, both from governmental and from privately operated organizations.

Illustrative of the foremost of these aeronautical research agencies are the National Advisory Committee for Aeronautics (NACA), Royal Aeronautical Society (RAS), Great Britain's Aeronautical Research Council (ARC), Canada's National Aeronautical Establishment (NAE), the College of Aeronautics at Cranfield, England, University of California's Institute of Technology (Cal Tech) Jet Propulsion Laboratory, Cornell Aeronautical Laboratory (CAL), University of Toronto Institute of Aerophysics (UTIA), the Aeronautical Research Institute of Sweden, France's National Office of Aeronautical Studies and Research (ONERA), United States Civil Aeronautics Administration (CAA), Technical Development and Eval- uation Center, and the United States Air Force and Naval Air Development and research units.

In short, the Aeronautical Reviews Department functions primarily to link together the Institute's wide-flung membership network. Not only does this documentation service act as a guide to the current literature of the field but it also serves to tell members and other interested individuals and organizations all over the world what is actually available for their use.

\section{Concluding Statement}

Within its editorial and informational activities, the IAS attempts to bring to its members and others in the aeronautical fields a two-fold service: I) to keep them informed of the current literature needed in their professional work by means of a published documentation service; and 2) to make this literature available to the limits of feasibility through professional and specialized library services. ${ }^{2}$

\footnotetext{
2 Thanks are due to John J. Glennon, the librarian, for his gracious cooperation in the preparation of this article.
}

\section{Postal Legislation}

College and university librarians will be interested in a measure to be introduced into the current session of Congress relating to the transmission of educational and cultural materials through the mails. This piece of legislation, sponsored by a group of educational and related organizations, is intended to establish more nearly uniform and logical rates for these materials.

Included in the proposed bill are the following provisions:

I. Special postal rates for interlibrary loan would be made applicable nation-wide as are all other rates on reading matter. Presently these special rates for interlibrary loan are limited to a single state or within the first three postal zones.

2. The present permit requirement would be deleted.

3. Bound typed theses, bound issues of periodicals, and other library materials, including photographs and manuscripts, could be sent through the mail on interlibrary loan at the library book rate.

4. Sheet music, which now goes at fourth class (parcel post) rate, would be treated as bound music and would receive the library rate on interlibrary loans and the book rate on other shipments.

5. Scholarly bibliographies that now go as advertising catalogs if they include publishers and prices would be treated as books and take the library rate for interlibrary loan and the book rate for other shipments.

6 . The general book rate would be held at its present level which is $8 \phi$ on the first pound and $4 \phi$ on each additional pound.

The passage of this bill will not affect the postal revenue by an appreciable degree but would place postal rates used by libraries on a more logical and consistent basis and would remove many of the present annoying impediments to effective library service. This measure will be introduced in the Congress in the very near future. It is hoped that librarians will write to their members of Congress in behalf of this measure after its introduction. Watch for further information regarding this piece of legislation.-Julia D. Bennett, ALA Washington Office. 